\title{
Strain Substrain Details
}

National Cancer Institute

\section{Source}

National Cancer Institute. Strain Substrain Details. NCI Thesaurus. Code C90460.

An indication of the strain and/or substrain of the organism. 